\title{
A unique phenotype in a patient with a rare triplication of the $22 q 11.2$ region and new clinical insights of the 22q11.2 microduplication syndrome: a report of two cases
}

\author{
Sara O. Vaz ${ }^{1}$, Renato Pires ${ }^{2,3}$, Luís M. Pires ${ }^{4}$, Isabel M. Carreira ${ }^{4,5,6}$, Rui Anjos ${ }^{7}$, Paula Maciel ${ }^{1+}$
} and Luisa Mota-Vieira ${ }^{2,3,8^{*}+}$

\begin{abstract}
Background: The rearrangements of the 22q11.2 chromosomal region, most frequently deletions and duplications, have been known to be responsible for multiple congenital anomaly disorders. These rearrangements are implicated in syndromes that have some phenotypic resemblances. While the 22q11.2 deletion, also known as DiGeorge/Nelocardiofacial syndrome, has common features that include cardiac abnormalities, thymic hypoplasia, characteristic face, hypocalcemia, cognitive delay, palatal defects, velopharyngeal insufficiency, and other malformations, the microduplication syndrome is largely undetected. This is mainly because phenotypic appearance is variable, milder, less characteristic and unpredictable. In this paper, we report the clinical evaluation and followup of two patients affected by 22q11.2 rearrangements, emphasizing new phenotypic features associated with duplication and triplication of this genomic region.

Case Presentation: Patient 1 is a 24 year-old female with 22q11.2 duplication who has a heart defect (ostium secundum atrial septal defect) and supernumerary teeth (hyperdontia), a feature previously not reported in patients with 22q11.2 microduplication syndrome. Her monozygotic twin sister, who died at the age of one month, had a different heart defect (truncus arteriousus). Patient 2 is a 20 year-old female with a 22q11.2 triplication who had a father with 22q11.2 duplication. In comparison to the first case reported in the literature, she has an aggravated phenotype characterized by heart defects (restrictive VSD and membranous subaortic stenosis), and presented other facial dysmorphisms and urogenital malformations (ovarian cyst). Additionally, she has a hemangioma planum on the right side of her face, a feature of Sturge-Weber syndrome.

Conclusions: In this report, we described hyperdontia as a new feature of 22q11.2 microdeletion syndrome. Moreover, this syndrome was diagnosed in a patient who had a deceased monozygotic twin affected with a different heart defect, which corresponds to a phenotypic discordance never reported in the literature. Case 2 is the second clinical report of 22q11.2 triplication and presents an aggravated phenotype in contrast to the patient previously reported.
\end{abstract}

Keywords: 22q11.2 microduplication syndrome, 22q11.2 triplication, Congenital heart defects

\footnotetext{
* Correspondence: Luisa.MQ.Vieira@azores.gov.pt

${ }^{\dagger}$ Equal contributors

${ }^{2}$ Molecular Genetics and Pathology Unit, Hospital of Divino Espírito Santo of

Ponta Delgada, EPE, Av. D. Manuel I, 9500-370 Ponta Delgada, São Miguel

Island, Azores, Portugal

${ }^{3}$ Biosystems \& Integrative Sciences Institute (BiolSI), Faculty of Sciences,

University of Lisboa, 1749-016 Lisboa, Portugal

Full list of author information is available at the end of the article
}

C Biomed Central

(c) 2015 Vaz et al. Open Access This article is distributed under the terms of the Creative Commons Attribution 4.0 International License (http://creativecommons.org/licenses/by/4.0/), which permits unrestricted use, distribution, and reproduction in any medium, provided you give appropriate credit to the original author(s) and the source, provide a link to the Creative Commons license, and indicate if changes were made. The Creative Commons Public Domain Dedication waiver (http://creativecommons.org/publicdomain/zero/1.0/) applies to the data made available in this article, unless otherwise stated. 


\section{Background}

The rearrangements of the $22 \mathrm{q} 11.2$ chromosomal region, specifically deletions and duplications, have been known to be responsible for multiple congenital anomaly disorders [1, 2]. The 22q11.2 deletion causes 22q11.2 deletion syndrome, also known as DiGeorge/ Velocardiofacial syndrome (DGS/VCFS), which has a prevalence estimated between 1:2000-1:17000 live births [3]. About $90 \%$ of these deletions are de novo, while $10 \%$ are inherited from an affected parent [4]. DGS/VCFS is characterized by a wide spectrum of clinical features that include: cardiac abnormalities, particularly conotruncal malformation; thymic and parathyroid hypoplasia; facial dysmorphisms; cognitive delay; palatal defects; velopharyngeal insufficiency; behavioral problems; hearing loss; limb deformity; and feeding difficulty, amongst others. The penetrance of each feature is variable, i.e., no single phenotype happens in all patients and none is obligatory [4-7].

Recently, 22q11.2 microduplication syndrome has been considered a different clinical entity than $22 \mathrm{q} 11.2$ deletion syndrome [2]. Recent data suggest that the frequency of duplications is approximately half of the deletions, mainly because duplications are largely undetected-phenotypic appearance is variable, milder, less characteristic, and unpredictable. Inherent methodological issues also contribute to difficulties in the diagnosis of this condition [2,8-10]. Based on the current literature, the phenotypes of 22q11.2 deletion and 22q11.2 microduplication syndromes sometimes overlap, but this is correlated to ascertainment bias and might represent a slight part of the wide range spectrum of these syndromes $[1,10,11]$.

The triplication of the $22 \mathrm{q} 11.2$ region was only reported in one study, in which the patient had a very mild phenotype, specifically speech delay, learning difficulties, and dysmorphic features (broad nasal bridge, hand/foot abnormality, epicanthal folds, eversion of the lateral eye lids, and bulbous nasal tip) [10].

In this paper, we report the clinical evaluation and follow-up of two patients affected by $22 \mathrm{q} 11.2$ rearrangements that we have recently characterized using molecular techniques [12]. Furthermore, we describe hyperdontia as a new feature of 22q11.2 microdeletion syndrome and report the clinical features of a patient who carries a 22q11.2 triplication, which is extremely important since it is the second case reported in the literature.

\section{Case presentation}

\section{Case 1}

The index case (corresponding to patient $\mathrm{C}$ in Pires et al. [12]) is a 24 year-old female who is the third child of consanguineous parents (a 26 year-old mother and a 30 year-old father). The patient was born at term (39 weeks of gestation), by vaginal delivery, with a birth weight of $2450 \mathrm{~g}\left(5^{\text {th }}\right.$ centile) and length of $47 \mathrm{~cm}\left(10^{\text {th }}\right.$ centile). Apgar scores were 1 at the first minute and 10 at the fifth minute. The patient had a monozygotic twin sister affected by truncus arteriosus, who underwent heart surgery, but died at the age of 1 month. The family history revealed another three deceased siblings: the first was a girl who died at the age of 9 months with a possible heart disease; the second was a stillborn boy; the third was a girl who died at the age of 13 months with a diagnosis of pulmonary atresia and ventricular septal defect (VSD). The mother has a history of hyperthyroidism and hypertension; the father has rheumatoid arthritis; both have learning difficulties. Maternal grandparents and the paternal grandfather died of unspecified heart disease. At the age of 9 years, the patient was suspected of having a heart condition due to the presence of a heart murmur and failure to thrive. An echocardiogram showed an ostium secundum atrial septal defect (ASD), which required heart surgery. Facial dysmorphisms were perceived, suggesting DGS/VCFS (Fig. 1a and b). She had recurrent upper respiratory tract infections that required adenoidectomy at the age of 15 . She also underwent otorhinolaryngology surgery, due to an infected auricular fistula, and received an otoplasty to correct a pinna deformity (Table 1).

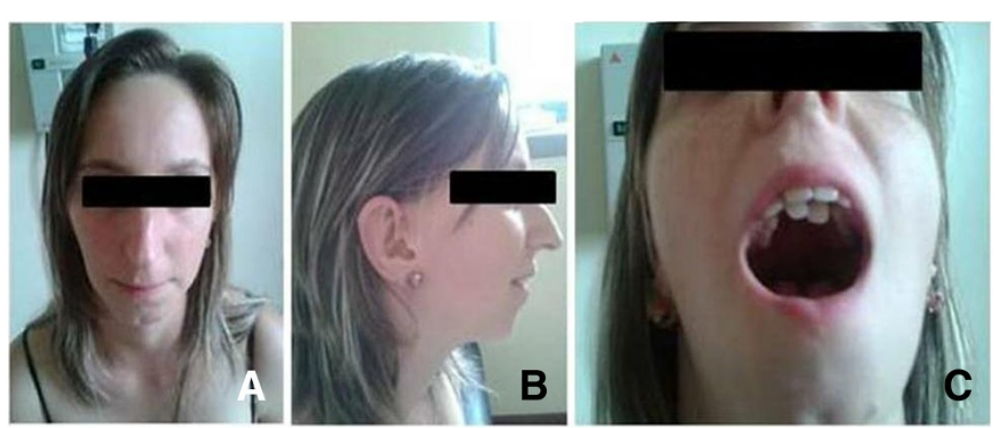

Fig. 1 Facial appearance of patient 1 with 22q11.2 microduplication syndrome. a Front view. b Side view. c Hyperdontia 
Table 1 Clinical characterization of two patients with 22q11.2 alterations and comparison with previously reported cases

\begin{tabular}{|c|c|c|c|c|c|c|}
\hline \multirow[t]{2}{*}{ Features } & \multirow[t]{2}{*}{ Case 1} & \multirow[t]{2}{*}{ Other cases ${ }^{a}$} & \multicolumn{2}{|l|}{ Case 2} & \multicolumn{2}{|c|}{ Yobb et al., 2005 [10] } \\
\hline & & & Patient & Father & Patient & Mother \\
\hline 22q11.2 region & Dup & Dup & Trip & Dup & Trip & Dup \\
\hline Age at last evaluation (years) & 24 & & 20 & 63 & 8 & \\
\hline Gender & $\mathrm{F}$ & & $\mathrm{F}$ & M & $\mathrm{F}$ & $\mathrm{F}$ \\
\hline Heart defect & + & + & + & & - & \\
\hline Velopharyngeal insufficiency & - & + & + & & - & \\
\hline Palatal defect & + & + & - & & - & \\
\hline Hearing impairment & - & + & + & & $+^{c}$ & \\
\hline Failure to thrive & - & + & - & & - & \\
\hline Roncopathy/sleep apnea & - & + & + & & - & \\
\hline Urogenital abnormalities & - & + & + & & - & \\
\hline Cognitive deficits & + & + & $++^{\mathrm{b}}$ & + & - & \\
\hline Psychiatric disorders & + & + & + & & & \\
\hline Behavioral problems & - & + & & & + & \\
\hline Seizures & - & + & - & & - & \\
\hline Headache & + & & $+^{\mathrm{b}}$ & & & \\
\hline Hand/foot abnormality & - & + & - & & + & + \\
\hline \multicolumn{7}{|l|}{ Dysmorphic features } \\
\hline \multicolumn{7}{|l|}{ - Head } \\
\hline Microcephaly & - & + & - & & \multirow[t]{3}{*}{-} & \\
\hline Long narrow face & + & + & + & & & \\
\hline Proeminent forehead & + & + & - & & & \\
\hline - Eyes & & & & & & \\
\hline Hypertelorism & + & + & + & & & \\
\hline Epicanthal folds & + & + & + & & + & \\
\hline Upslanting palpebral fissures & + & + & - & & & \\
\hline Downslanting palpebral fissures & - & + & + & & & \\
\hline Superior placement of eyebrows & + & + & - & & & \\
\hline Strabismus & - & + & $+^{\mathrm{b}}$ & & & \\
\hline Myopia & + & + & $+^{\mathrm{b}}$ & & & \\
\hline - Nose & & & & & & \\
\hline Broad nasal bridge & + & + & - & & & \\
\hline Proeminent nose & + & + & + & & & \\
\hline Long philtrum & + & & + & & & \\
\hline Smooth philtrum & + & + & + & & & \\
\hline - Ears & & & & & & \\
\hline Dysplastic ears & + & + & - & & & \\
\hline Preauricular fistula & + & + & - & & & \\
\hline - Mouth & & & & & & \\
\hline Micrognathia & + & + & - & & - & \\
\hline Retrognathia & + & + & + & & & \\
\hline Supernumerary teeth (hyperdontia) & + & & - & & & \\
\hline Dental cavities & + & + & + & & & \\
\hline
\end{tabular}


Table 1 Clinical characterization of two patients with 22q11.2 alterations and comparison with previously reported cases (Continued)

\begin{tabular}{|c|c|c|c|}
\hline \multicolumn{4}{|l|}{ Additional features } \\
\hline - Recurrent infections & + & + & + \\
\hline \multicolumn{4}{|l|}{ - Skeletal } \\
\hline Hiperlaxity & - & + & - \\
\hline Other & - & + & - \\
\hline - Dermatologic abnormalities & - & & $+^{\mathrm{b}}$ \\
\hline - Allergies & + & & + \\
\hline
\end{tabular}

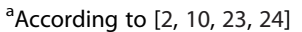

${ }^{\text {b }}$ Sturge-Weber syndrome's symptoms that are likely unrelated to the 22q11.2 triplication

'Hearing impairment was probably secondary to otitis media

Currently, the patient has mild developmental delay and learning difficulties, hyperdontia (supernumerary teeth; Fig. 1c), and dental cavities. Nonetheless, she is living an independent life and is currently married. In order to investigate the presence of 22q11.2 deletion, which is associated with DGS/VCFS, and other genomic alterations, we performed multiplex ligation-dependent probe amplification (MLPA) and array comparative genomic hybridization (array-CGH), respectively [12]. Both techniques detected a de novo duplication (1:2, one normal chromosome and a 22q11.2 duplication in the other) of $2.5 \mathrm{Mb}$ (nucleotide positions $18,894,835$ to $21,464,119$ ) [12], supporting the diagnosis of 22q11.2 microduplication syndrome.

\section{Case 2}

This patient, a 20 year-old female who corresponds to patient B in Pires et al. [12], is the eighth child of a 42 year-old mother and a 43 year-old father; the latter presents mild intellectual disability and learning difficulties. She was born at 38 weeks of gestation by spontaneous vaginal delivery. The patient has seven normal siblings. At birth, she weighed $2950 \mathrm{~g}$ ( $5^{\text {th }}$ centile), her height was $46 \mathrm{~cm}$ ( $5^{\text {th }}$ centile), and head circumference was $34 \mathrm{~cm}\left(25^{\text {th }}\right.$ centile). Apgar scores were 9 at the first minute and 10 at the fifth minute. She had a hemangioma planum on the right side of her face, low set ears, and convergent strabismus on the right eye (Table 1). In infancy, the transfontanelar ultrasound and the computed tomography (CT) scan of the head were both normal. In the first years of her life, she was diagnosed with failure to thrive, developmental delay, hearing impairment, multiple upper respiratory infections, and restrictive VSD and membranous subaortic stenosis, which required surgery. At 13 years of age, a large ovarian cyst was diagnosed.

At 15 years of age, she was diagnosed with SturgeWeber syndrome. A CT scan showed ocular asymmetry with greater dimensions of the left eye, hypercaption of contrast product in the external posterior wall of the right eyeball, and an almost absent mastoid pneumatization.
Currently, she has moderate cognitive and language impairment, and is dependent for most daily activities. Due to the heart defects, we performed the analysis of the of 22q11.2 region by MLPA, fluorescent in situ hybridization (FISH), and array-CGH [12]. MLPA identified four copies of this region, whereas FISH confirmed a tetrasomy (1:3, one normal chromosome and a $22 q 11.2$ triplication in the other) that was most likely inherited from a paternal duplication (1:2) with an extra copy [12]. Moreover, the array-CGH showed a triplication of $3 \mathrm{Mb}$ (nucleotide positions 18,661,724 to 21,917,251) [12].

\section{Conclusions}

The two cases described illustrate the phenotypic variability associated with rearrangements of the $22 q 11.2$ chromosomal region. We establish the similarities and differences between the two patients with the $22 \mathrm{q} 11.2$ variants, revealing hyperdontia as a new characteristic of the 22q11.2 microduplication syndrome and new features concerning triplication of the $22 \mathrm{q} 11.2$ region.

Only a few patients with 22q11.2 microduplication syndrome and concomitant heart defects have been reported [11, 13]. Patient 1 had an ASD that required surgery. At birth, the diagnosis of DGS/VCFS was suggested due to facial dysmorphisms, failure to thrive, and a strong family history of heart diseases and sudden death syndrome. At that time it was not possible to perform specific techniques to diagnose $22 \mathrm{q} 11.2 \mathrm{du}$ plication. Even though having mild developmental delay, she lives an independent life. It is essential to emphasize two clinical aspects. First, the existence of an anomaly like hyperdontia, which was never reported as being associated to the $22 \mathrm{q} 11.2$ microduplication syndrome (Table 1). Second, the fact that her monozygotic twin sister, who died at the age of one month, had a different heart defect, which demonstrate that other factors - post-zygotic genetic, epigenetic, environmental and stochastic - could affect human heart development. These factors may contribute to the discordance of congenital heart disease (CHD) in monozygotic twins [14]. 
Despite this discordance that has been described in monozygotic twins with DGS/VCFS $[15,16]$, it was never associated with 22q11.2 microduplication syndrome.

Patient 2, who has a father with 22q11.2 duplication and a normal mother, presents a triplication of the $22 q 11.2$ region and, to our knowledge, this is the second case described in literature [10,12]. In comparison to the first reported case, who presented speech delay, learning difficulties, and dysmorphic features, patient 2 has an aggravated phenotype characterized by heart defects (restrictive VSD and membranous subaortic stenosis), and presented other facial dysmorphisms and urogenital malformations (ovarian cyst; Table 1). The patient also has a hemangioma planum on the right side of her face. This latter sign is consistent with one of the diagnostic criteria of Sturge-Weber syndrome. As we know, this syndrome is a sporadic congenital neurocutaneous disorder, caused by a somatic activating mutation (c.548G > A, p.Arg183Gln) in GNAQ gene [17]. Clinically, it is characterized by the presence of nevus flammeus (port-wine stain), involving the area of the first sensory branch of the trigeminal nerve. The second and third trigeminal branches might be involved, by cerebral venous malformations (ipsilateral leptomeningeal angiomatosis) and by glaucoma with ocular capillary venous vascular malformations [18-20]. Sturge-Weber syndrome has been associated with epilepsy, behavioral disorders, cognitive impairment, headaches, spastic hemiparesis, and visual fields defects [18-22]. In fact, patient 2 presents similar features (Table 1) and possibly has the somatic mutation c.548G > A (p.Arg183Gln) in the GNAQ gene.

In summary, here we report hyperdontia as a new feature of 22q11.2 microdeletion syndrome. This syndrome was diagnosed in a patient who had a deceased monozygotic twin affected with a different heart defect, which corresponds to a phenotypic discordance never reported in the literature. Moreover, we reinforce that physicians should pay attention to the resemblances between 22q11.2 microduplication and deletion syndromes, in order to avoid misdiagnosis. Therefore, these two syndromes should be considered in the presence of a patient with a dysmorphic face associated with CHD, thymic hypoplasia, developmental delay, and other malformations. Patients with triplication of 22q11.2 region are extremely rare and case 2 presented an aggravated phenotype in contrast to the previously reported, which has a milder phenotype. Both triplication cases fit within the 22q11.2 duplication spectrum. Some factors may contribute to their phenotypic variability, such as differences in genetic background, different genetic dosages, abnormalities in the parent of origin or imprinted chromosomal material (e.g., uniparental disomy). Finally, we suggest that duplications and triplications could be underdiagnosed, particularly if evaluated by FISH in metaphase spreads. Molecular tests, like MLPA or arrayCGH, could be more adequate.

\section{Consent}

This work was approved by the Health Ethics Committee from the Hospital of Divino Espírito Santo of Ponta Delgada, EPE. Written informed consent for the patients' inclusion in the study was obtained from themselves and their parents. Patient 1 gave informed consent to publish her clinical information and photos. Patient 2 authorized the publication of her clinical data, however she did not allow physicians to publish her photos. The copies of the written consents are available for review by the Editor of this Journal.

\section{Abbreviations}

DGSNCFS: DiGeorge/Velocardiofacial syndrome; VSD: Ventricular septal defect; ASD: Atrial septal defect; MLPA: Multiplex ligation-dependent probe amplification; array-CGH: Array Comparative genomic hybridization; $\mathrm{CT}$ : Computed tomography; FISH: Fluorescent in situ hybridization; CHD: Congenital heart disease.

\section{Competing interests}

The authors declare that they have no competing interests.

\section{Authors' contributions}

SOV was involved in patient care review, organized sample collection, performed the literature review, and wrote the manuscript. RP organized sample collection, implemented/carried out MLPA experiments, and revised the manuscript. LMP participated in the implementation of MLPA and performed array-CGH assays. IMC advised the study and critically read the manuscript. RA was involved in patient care and revised the manuscript. PM was involved in patient care and revised the manuscript. LMV advised the study, organized sample collection, and revised the manuscript. All authors read and approved the final manuscript.

\section{Acknowledgements}

We thank the patients and their parents for their cooperation and support, and for providing consent for publication. We are grateful to the hospital nurse Pedro Brazio for his assistance with managing the patients. We would also like to thank Arya Ibrahim Kermanshah, Henna Chandel, and Ruben Neves, students from The Pennsylvania State University, University of Kentucky, and Fairfield University, respectively, for revising the English language manuscript. We are also grateful to Dr. Carlos Pereira Duarte for his helpful contribution to the establishment of the Azorean Registry of CHD. RP is a post-doctoral fellow (ref. M3.1.7/F/011/2011) from "Fundo Regional para a Ciência e Tecnologia" of the Government of the Azores. The present work was also supported by grants from "Direção Regional da Ciência e Tecnologia" (DRCT) of the Government of the Azores and by centre grant (to BiolSI, Centre Reference: UID/MULTI/04046/2013), from FCT/MCTES/PIDDAC, Portugal.

\section{Author details}

${ }^{1}$ Department of Pediatrics of Hospital of Divino Espírito Santo of Ponta Delgada, EPE, Av. D. Manuel I, 9500-370 Ponta Delgada, São Miguel Island, Azores, Portugal. ${ }^{2}$ Molecular Genetics and Pathology Unit, Hospital of Divino Espírito Santo of Ponta Delgada, EPE, Av. D. Manuel I, 9500-370 Ponta Delgada, São Miguel Island, Azores, Portugal. ${ }^{3}$ Biosystems \& Integrative Sciences Institute (BiolSI), Faculty of Sciences, University of Lisboa, 1749-016 Lisboa, Portugal. ${ }^{4}$ Cytogenetics and Genomics Laboratory, Faculty of Medicine, University of Coimbra, 3000-354 Coimbra, Portugal. ${ }^{5}$ Centro de Investigação em Meio Ambiente, Genética e Oncobiologia (CIMAGO), Faculty of Medicine, University of Coimbra, 3000-354 Coimbra, Portugal. ${ }^{6}$ Centre of Neurosciences (CNC), University of Coimbra, 3000-354 Coimbra, Portugal. ${ }^{7}$ Department of Pediatric Cardiology, Hospital of Santa Cruz, Av. Prof. Dr. Reinaldo dos Santos, 2790-134 Carnaxide, Portugal. ${ }^{8}$ Instituto Gulbenkian de Ciência, Rua da Quinta Grande, 6, 2780-156 Oeiras, Portugal. 
Received: 10 November 2014 Accepted: 13 August 2015

Published online: 22 August 2015

\section{References}

1. Piccione M, Vecchio D, Cavani S, Malacarne M, Pierluigi M, Corsello G. The first case of myoclonic epilepsy in a child with a de novo 22q11.2 microduplication. Am J Med Genet Part A. 2011;155A:3054-9.

2. Ensenauer RE, Adeyinka A, Flynn HC, Michels W, Lindor NM, Dawson DB, et al. Microduplication 22q11.2, and emerging syndrome: clinical, cytogenetic and molecular analysis of thirteen patients. Am J Hum Genet. 2003;73:102740.

3. Ryan AK, Goodship JA, Wilson DI, Philip N, Levy A, Seidel H, et al. Spectrum of clinical features associated with interstitial chromossome 22q11.2 deletions: a European collaborative study. J Med Genet. 1997;34:798-804.

4. Robin NH, Sprintzen RJ. Defining the clinical spectrum of deletion 22q11.2. J Pediatr. 2005;147:90-6.

5. Wu D, Chen Y, Xu C, Wang K, Wang H, Zheng F, et al. Characteristic face: a key indicator for direct diagnosis of 22q11.2 deletions in Chinese velocardiofacial syndrome patients. Plos ONE. 2013;8:e54404.

6. Shpritzen RJ. Velo-cardio-facial syndrome: 30 years of study. Dev Disabil Res Rev. 2008;14:3-10.

7. Bassett AS, McDonald-McGinn DM, Devriendt K, Digilio MC, Goldenberg P, Habel A, et al. Pratical guidelines for managing patients with 22q11.2 deletion syndrome. J Pediatr. 2011;159:332-9.

8. Emanuel BS. Molecular mechanisms and diagnosis of chromossome $22 q 11.2$ rearrangements. Dev Disabil Res Rev. 2008;14:11-8.

9. Wentzel C, Fernström M, Ohrner Y, Annerén G, Thuresson AC. Clinical variability of 22q11.2 duplication syndrome. Eur J Med Genet. 2008;51:501-10.

10. Yobb TM, Sommerville MJ, Willat L, Fith HV, Harrison K, Mackenzie J, et al. Microduplication and triplication of 22q11.2: a highly variable syndrome. Am J Hum Genet. 2005;76:865-76.

11. Portnöi M-F. Microduplication 22q11.2: A new chromosomal syndrome. Eur J Med Genet. 2009;52:88-93.

12. Pires R, Pires LM, Vaz SO, Maciel P, Anjos R, Moniz R, et al. Screening of copy number variants in the $22 q 11.2$ region of congenital heart disease patients from the São Miguel Island, Azores, revealed the second patient with a triplication. BMC Genet. 2014;15:115.

13. Laitenberger G, Donner B, Gebauer J, Hoehn T. D-Transposition of the great arteries in a case of microduplication 22q11.2. Pediatr Cardiol. 2008:29:1104-6.

14. Breckpot J, Thienpont B, Gewillig M, Allegaert K, Vermeesch JR, Devriendt K. Differences in copy number variation between discordant monozygotic twins as a model for exploring chromossomal mosaicism in congenital heart defects. Mol Syndromol. 2011;2:81-7.

15. Goodship J, Cross I, Scambler P, Burn J. Monozygotic twins with chromosome 22q11 deletion and discordant phenotype. J Med Genet. 1995;32:746-8.

16. Halder A, Jain M, Chaudhary I, Varma B. Chromosome 22q11.2 microdeletion in monozygotic twins with discordant phenotype and deletion size. Mol Cytogenet. 2012;5:13.

17. Shirley MD, Tang H, Gallione CJ, Baugher JD, Frelin LP, Cohen B, et al. Sturge-Weber syndrome and port-wine stains caused by somatic mutation in GNAQ. N Engl J Med. 2013;368:1971-9.

18. Lo W, Marchuk DA, Ball KL, Juhász C, Jordan LC, Ewen JB, et al. Updates and future horizons on the understanding, diagnosis, and treatment of SturgeWeber syndrome brain involvement. Dev Med Child Neurol. 2012;54:214-23.

19. Riela AR, Stump DA, Roach ES, McLean Jr WT, Garcia JC. Regional cerebral blood flow characteristics of the Sturge-Weber syndrome. Pediatr Neurol. 1985;1:85-90.

20. Comi AM. Advances in Sturge-Weber syndrome. Curr Opin Neurol. 2006;19:124-8.

21. Sujansky E, Conradi S. Outcome of Sturge-Weber syndrome in 52 adults. Am J Med Genet. 1995;57:35-45.

22. Bodensteiner J, Roach ES. Sturge-Weber syndrome: introduction and overview. In: Bodensteiner J, Roach ES, editors. Sturge-weber syndrome. Mount Freedom: Sturge Weber Foundation; 1999. p. 1-10.

23. Ou Z, Berg JS, Yonath H, Enciso VB, Miller DT, Picker J, et al. Microduplications of 22 q11.2 are frequently inherited and are associated with variable phenotypes. Genet Med. 2008;10:267-77.
24. Bi W, Probst FJ, Wiszniewska J, Plunkett K, Roney EK, Carter BS, et al. Co-occurrence of recurrent duplications of the DiGeorge syndrome region on both chromosome 22 homologues due to inherited and de novo events. J Med Genet. 2012;49:681-8.

\section{Submit your next manuscript to BioMed Central and take full advantage of:}

- Convenient online submission

- Thorough peer review

- No space constraints or color figure charges

- Immediate publication on acceptance

- Inclusion in PubMed, CAS, Scopus and Google Scholar

- Research which is freely available for redistribution 